\title{
qPCR estimates of Babesia bovis and Babesia bigemina infection levels in beef cattle and Rhipicephalus microplus larvae
}

\author{
Rodrigo Giglioti $^{1}$ (D) Henrique Nunes de Oliveira ${ }^{1} \cdot$ Cintia Hiromi Okino $^{2}$. \\ Márcia Cristina de Sena Oliveira ${ }^{2}$
}

Received: 23 March 2018 / Accepted: 28 April 2018 / Published online: 4 May 2018

(C) Springer International Publishing AG, part of Springer Nature 2018

\begin{abstract}
Babesia spp. are tick-transmitted intraerythrocytic apicomplexan parasites that infect wild and domestic animals. Babesia bovis and B. bigemina are endemic and responsible for enormous economic losses to the livestock industry in most of the Brazilian territory, wherein the tick Rhipicephalus microplus is the unique vector. Better understanding of epidemiology and parasite-host interactions may improve the tools for disease control and genetic management for selection of resistant animals. This study aimed to detect, quantify and measure the correlation between B. bigemina and B. bovis infection levels in bovine blood and into tick, by absolute quantification of hemoparasite DNA using qPCR. Blood bovine samples and larvae pools from 10 engorged $R$. microplus females were collected from each Canchim heifers $(5 / 8$ Charolais $+3 / 8$ zebu, $n=36)$. All evaluated samples were positive for both Babesia species tested. Correlations of $B$. bovis and B. bigemina levels between cattle and tick host were 0.58 and 0.66 , respectively. These high positive correlation coefficients indicate that parasitemia load in the bovine may be dependent on or may determine the parasitemia load in the ticks.
\end{abstract}

Keywords Correlation $\cdot$ Infection $\cdot$ Babesiosis $\cdot$ Cattle $\cdot$ Ticks

\section{Introduction}

Bovine babesiosis are tick-borne diseases that cause fever, anemia, hemoglobinuria and ataxia, leading to significant losses for the livestock industry in tropical and subtropical regions of the world (Uilenberg 1995; Brown and Palmer 1999; Gohil et al. 2013). Catthe that recover from acute infection remains persistently infected and can be continuing

Rodrigo Giglioti

gigliotirodrigo@gmail.com

1 Universidade Estadual Júlio de Mesquita Filho, Unesp Jaboticabal, São Paulo, Brazil

2 Embrapa Pecuária Sudeste, Rodovia Washington Luiz, Km 234, CP 339, São Carlos, São Paulo 13560-970, Brazil 
infecting ticks (Calder et al. 1996; Brown and Palmer 1999; Bock et al. 2004; Oliveira et al. 2005).

Endemic stability for B. bovis and B. bigemina is common in most of regions from Brazil (Kessler et al. 1983; Vidotto et al. 1997), wherein qPCR assays have been suscessfully applied for detection and quantification of these pathogens (Ramos et al. 2011; Bilhassi et al. 2014; Giglioti et al. 2016, 2017, 2018). Recent studies have demonstrated no association between Babesia DNA levels in naturally infected cattle and tick counts (Giglioti et al. 2016, 2017, 2018). However, studies regarding association between babesiosis infection levels in ticks and cattle host blood remain still scarce.

In this context, differential transmissibility rates of $B$. bovis and B. bigemina to the ticks was previously associated to bovine host's age (Oliveira-Sequeira et al. 2005). In this study, carried in endemic area for these hemoparasites, presenting similar infection rates for both Babesia species in adult and young cattle, it was verified that engorged females ticks collected from calves produced significantly higher frequency of eggs infected with $B$. bigemina compared to those infected with B. bovis, while no differences were observed for cows.

Similar B. bovis transmissibility rates from persistently or acutely infected calves to larval progeny through engorged tick females were observed in experimentally $B$. bovis challenged animals, leading authors to conclude that risk associated with introduction of both animals to non-endemic are for this pathogen is equal (Howell et al. 2007a). In another study, positive correlations were observed between $B$. bovis levels in host animal and percentage of engorged females containing high levels of kinetes in hemolymph and also between parasite levels in larval progeny and kinete levels in hemolymph of adult females, while no correlations were observed between kinete levels in hemolymph with percentage of infection rates of larval progeny (Howell et al. 2007b).

This study was carried aiming to better elucidate cattle host-babesia-tick triad interactions, and to evaluate correlations between the B. bovis and B. bigemina infection levels in naturally infected cattle and respective ticks.

\section{Materials and methods}

\section{Experimental area, animals and sample collections}

The experiment was conducted at the research farm from Embrapa Livestock Southeast (Embrapa Pecuária Sudeste), located at São Carlos, São Paulo state $\left(22^{\circ} 01^{\prime} \mathrm{S}\right.$ and $\left.47^{\circ} 53^{\prime} \mathrm{W}\right)$. This region is considered endemic for the occurrence of $R$. microplus and the hemoparasites transmitted by these ticks (Oliveira et al. 2008; Giglioti et al. 2018). Thirty six Canchim heifers (5/8 Charolais $+3 / 8$ Zebu) with 10-13 months of age, naturally infested with ticks, were submitted to blood sampling (using EDTA vacutainer tubes) and collection of engorged female ticks (body lengths greater $>5 \mathrm{~mm}$ ) during spring season (October 2013). Acaricide treatments of animals were avoided during 50 days before samplings. For each animal, groups of 10 engorged female ticks presenting similar weight were washed, dried, placed in sterile Petri dishes and incubated in a BOD (biochemical oxygen demand) chamber at $27 \pm 1{ }^{\circ} \mathrm{C}$ under relative humidity $>90 \%$. At the end of laying period (15th day), eggs from all 10 engorged females per animal were pooled in transparent plastic syringes to verify the larval hatching rate. All procedures have been approved by Embrapa Southeast Livestock Ethical Committee for Animal Experimentation (CEUA-EMBRAPA), 
in accordance with ethical principles and guidelines of animal experimentation adopted by the Brazilian College of Experimentation (Process Number 03/2014).

\section{DNA extraction}

Blood samples were processed for total DNA extraction using Easy-DNA ${ }^{\mathrm{TM}}$ kit (Invitrogen USA, catalog number K180001) according to the manufacturer's protocol (Protocol \#2-30 Minute DNA Extraction from Blood Samples). DNA extractions from tick larval pools (approximately 100 larvae) were performed in two steps. In the first, the larval pool was transferred and macerated into $1.5 \mathrm{~mL}$ microtubes using plastic pistil and liquid nitrogen during $15 \mathrm{~s}$. The macerated was supplemented with $100 \mu \mathrm{L}$ of DNA isolation buffer $(1667 \mu \mathrm{L}$ of $3 \mathrm{M} \mathrm{KCl} ; 600 \mu \mathrm{L}$ of $1 \mathrm{M}$ Tris-Cl, pH 8.5; $400 \mu \mathrm{L}$ of $1 \mathrm{M}$ Tris-Cl, pH 8.0; $7333 \mu \mathrm{L}$ of ultrapure water) and macerated with the frozen pistil for another $15 \mathrm{~s}$. The homogenized material was incubated at boiling temperature during $5 \mathrm{~min}$ and processed with Axygen ${ }^{\mathrm{TM}}$ Axyprep $^{\mathrm{TM}}$ Multisource Genomic DNA MiniPrep Kit (No. 14-223-003) protocol "Purification of Genomic DNA from Animal Tissues", as recommended by the manufacturer. All DNA samples were kept at $-80{ }^{\circ} \mathrm{C}$ until further analysis.

\section{qPCR}

Absolute quantification of B. bovis and B. bigemina DNA levels were carried in a CFX ${ }^{\mathrm{TM}}$ Real-Time PCR Detection System (BioRad), using SsoFast ${ }^{\mathrm{TM}}$ EvaGreen $^{\circledR}$ Supermix (Bio$\mathrm{Rad}$ ) reagents and primers targeting mitochondrial cytochrome b gene (Buling et al. 2007). Standard curves and reaction conditions were performed as described (Giglioti et al. 2016, 2017, 2018). Samples and controls (positive and negative) were analyzed in duplicate. Negative and positive samples of $R$. microplus larval DNA for Babesia spp. obtained from the microbial collection of Embrapa Southeast Livestock, São Carlos, São Paulo state, were also included as negative and positive controls, respectively.

\section{Statistical analysis}

The analyses were carried out using the SAS statistical package (SAS 2002). DNA copy numbers $(\mathrm{CN})$ data were transformed into $\log _{10}(\mathrm{n}+1)$ to approximate the normal distribution. After transformation, the data were analyzed using the PROC GLM and PROC CORR procedures. The first model was used to compare means of the Babesia spp. infection levels between each host. The CN Means values were compared by the Tukey test $(p \leq 0.05)$. In the second analysis, the relationships of transformed $\mathrm{CN}$ data of $\mathrm{B}$. bovis and B. bigemina between ticks and cattle were established using Pearson's correlation coefficient.

\section{Results and discussion}

High positive frequencies of both Babesia species were found, as all tested samples were positive, either from tick or bovines. The means of $B$. bovis and B. bigemina DNA copies followed by standard errors in cattle were $2.58 \pm 0.45$ and $2.85 \pm 0.41$, respectively, while for ticks the values were $1.96 \pm 0.84$ and $1.96 \pm 0.84$, respectively. There were no significant differences between DNA copy levels observed in cattle and ticks, for both Babesia species. Similar findings were already described for previous 
experiments performed in this experimental region, classified as endemically stable for the occurrence of babesiosis (Oliveira et al. 2005, 2008; Giglioti et al. 2018). Despite existence of several studies evaluating babesiosis infection levels in ticks (Cafrune and Aguirre 1995; Oliveira et al. 2005; Oliveira-Sequeira et al. 2005; Ica et al. 2007; Oliveira et al. 2008), there are still few studies which have performed the comparative evaluation in the respective host. In this sense, there were no differences of $B$. bovis transovarial infection rates in the larval progeny from $R$. microplus females that fed on persistently infected calves or those females that fed on acutely infected calves (Howell et al.,2007a). In another study, Howell et al. (2007b) found a correlation between $B$. bovis infection levels in the blood of clinically affected cattle and kinete levels in the hemolymph of adult female $R$. microplus ticks. Although, in the same study, B. bovis infection levels in the engorged females hemolymph have not correlated to infection rates of larval progeny. Since we observed high correlations of Babesia spp. infection levels between the vertebrate and invertebrate hosts, our results diverge from these previous studies. Main reasons which may explain this difference are due to differential nature of infection (experimental versus natural field infection), and to our method for Babesia levels quantification.

According to Mahoney and Mirre (1971), there is a low transmissibility percentage of transovarial transmission of Babesia spp. even if they become infected from animals in the acute disease, characterized by markedly parasitemia. In this infection phase, the transmission rates ranges from 20 to 40 and 0.5 to $14.5 \%$, for B. bigemina and $B$. bovis, respectively. Therefore, despite low transovarial transmissibility rates, our method comprised quantification of Babesia DNA levels from pools containing approximately 100 larvae (hatched from eggs laid by 10 engorged females), which may explain high positivity. Furthermore, we evaluated young animals (10-13 months of age) which may also have contributed to observed high infection levels. Oliveira et al. (2005) have observed higher frequency of Babesia spp. kinetes in ticks hemolymph collected from calves (77/260) compared to those collected from cows (7/236), by direct microscopy. Higher B. bigemina infection levels in calves compared to adults were also reported by Oliveira-Sequeira et al. (2005), wherein frequency of B. bigemina positive samples $(156 / 258)$ was higher than frequency of $B$. bovis infection $(23 / 258)$. In our study, the infection levels between Babesia species did not differ.

Although it is well established that the larval phase form of $R$. microplus does not transmit B. bigemina to the bovine host (Radostits et al. 2008), in the present study it was possible to quantify the DNA levels of this hemoparasite in a pool of approximately 100 larvae. According to Riek (1964), B. bigemina is only transmitted to cattle by infected nymphs and adults due to the presence of infective sporozoites of $B$. bigemina only 8-10 days after larval attachment. Regarding $B$. bovis infection, larvae are able to infect the host within 2-3 days after attachment, but the infectivity does not persist after the larval stage (CFSPH 2008).

High correlation coefficients $(p<0.01)$ of DNA levels of $B$. bovis and B. bigemina were found between cattle and ticks: 0.58 and 0.66 , respectively (Fig. 1). Concerning correlation analysis, our study showed a high association of Babesia spp. between cattle and tick DNA samples. The DNA copy numbers of B. bovis and B. bigemina between the ticks and cattle indicates that parasitemia loads in the bovine is dependent or will determine the parasitemia loads in the ticks. Further studies must be performed to better understand this parasite-host interaction, including elucidation of which factors may are influencing on transovarial transmission fluctuations. 

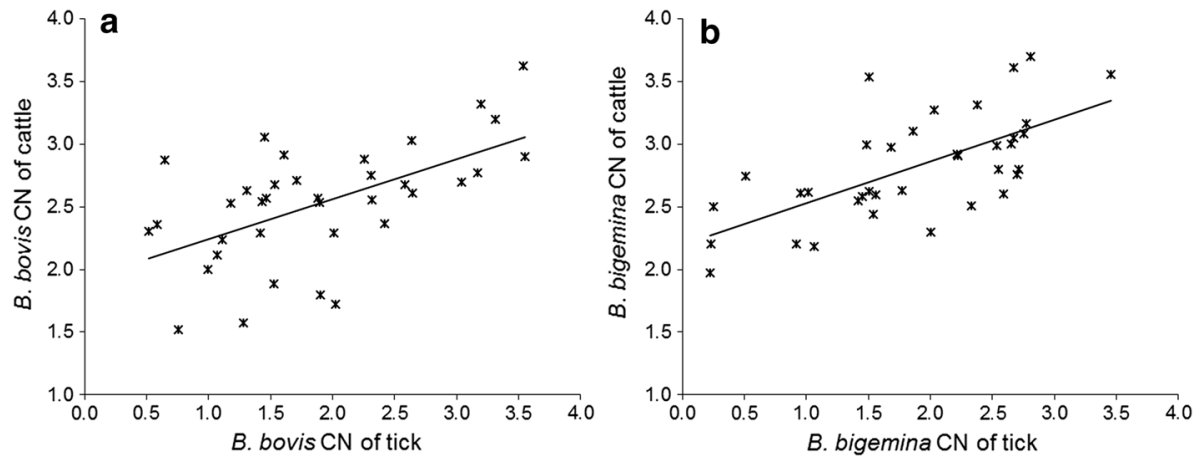

Fig. 1 Scatter plot correlation of copy number values of Babesia bovis (a) and B. bigemina (b) between DNA samples from cattle and ticks

Acknowledgements This research project was supported by the São Paulo State Research Support Foundation (FAPESP) (Grant \#2013/20513-5, 2016/07216-7) and the Brazilian Agricultural Research Corporation (Embrapa SEG 02.12.02.008.00.00).

\section{References}

Bilhassi TB, Oliveira HN, Ibelli AMG, Giglioti R, Regitano LCA, Oliveira-Sequeira TCG, Bressani FA, Malagó W, Resende FD, Oliveira MCS (2014) Quantitative study of Babesia bovis infection in beef cattle fromSão Paulo state, Brazil. Ticks Tick Borne Dis 5:234-238

Bock R, Jackson L, De Vos A, Jorgensen W (2004) Babesiosis of cattle. Parasitology 129:S247-S269

Brown WC, Palmer GH (1999) Designing blood-stage vaccines against Babesia bovis and Babesia bigemina. Parasitol Today 15:275-281

Buling A, Criado-Fornelio A, Asenzo G, Benitez D, Barba-Carretero JC, Florin-Christensen M (2007) A quantitative PCR assay for the detection and quantification of Babesia bovis and B. bigemina. Vet Parasitol 147:16-25

Cafrune MM, Aguirre DH (1995) Experimental studies of the rate of infection of Boophilus microplus eggs with Babesia bovis. Res Vet Sci 58:284-285

Calder JAM, Reddy GR, Chieves L, Courtney CH, Littell R, Livengood JR, Norval RAI, Smith G, Dame JB (1996) Monitoring Babesia bovis in cattle using PCR-based tests. J Clin Microbiol 34:2748-2755

CFSPH (Center for Food Security and Public Health) (2008) Bovine babesiosis. Iowa State University, Ames

Giglioti R, Oliveira HN, Santana CH, Ibelli AMG, Néo TA, Bilhassi TB, Rabelo MD, Machado RZ, Brito LG, Oliveira MCS (2016) Babesia bovis and Babesia bigemina infection levels estimated by qPCR in Angus cattle from an endemic area of São Paulo state, Brazil. Ticks Tick-Borne Dis 7:657-662

Giglioti R, Oliveira HN, Ibelli AMG, Bilhassi TB, Néo TA, Santana CH, Rabelo MD, Machado RZ, Chagas ACS, Oliveira MCS (2017) Neither quantification by qPCR nor quantitative Elisa can be used to discriminate Angus cattle for resistance/susceptibility to Babesia bovis. Ticks Tick-Borne Dis 8(3):335-340

Giglioti R, Oliveira HN, Bilhassi TB, Portilho AI, Okino CH, Marcondes CR, Oliveira MCS (2018) Estimates of repeatability and correlations of hemoparasites infection levels for cattle reared in endemic areas for Rhipicephalus microplus. Vet Parasitol 250:78-84

Gohil S, Susann H, Svenja G, Brian MC (2013) Bovine babesiosis in the 21st century: advances in biology and functional genomics. Int J Parasitol 43:125-132

Howell JM, Ueti MW, Palmer GH, Scoles GA, Knowles DP (2007a) Transovarial transmission efficiency of Babesia bovis tick stages acquired by Rhipicephalus (Boophilus) microplus during acute infection. J Clin Microbiol 45(2):426-431

Howell JM, Ueti MW, Palmer GH, Scoles GA, Knowles DP (2007b) Persistently infected calves as reservoirs for acquisition and transovarial transmission of Babesia bovis by Rhipicephalus (Boophilus) microplus. J Clin Microbiol 45(10):3155-3159 
Ica A, Vatansever Z, Yildirim A, Duzlu O, Inci A (2007) Detection of Theileria and Babesia species in ticks collected from cattle. Vet Parasitol 148:156-160

Kessler RH, Madruga CR, Schenk MA, Ribeiro OC (1983) Babesiose cerebral por Babesia bovis em bezerros no Estado do Mato Grosso do Sul. Pesqui Agropecu Bras 18:931-935

Mahoney DF, Mirre GB (1971) Bovine babesiosis: estimation of infection rates in the tick vector Boophilus microplus (Canestrini). Ann Trop Med Parasitol 65:309-317

Oliveira MCS, Oliveira-Sequeira TCG, Araujo JP Jr, Amarante AFT, Oliveira HN (2005) Babesia spp. infection in Boophilus microplus engorged female and eggs in São Paulo State, Brazil. Vet Parasitol 130:61-67

Oliveira MCS, Oliveira-Sequeira TCG, Regitano LCA, Alencar MM, Néo TA, Silva AM, Oliveira HN (2008) Detection of Babesia bigemina in cattle of different genetic groups and in Rhipicephalus (Boophilus) microplus tick. Vet Parasitol 155:281-286

Oliveira-Sequeira TCG, Oliveira MCS, Araujo-Júnior JP, Amarante AFT (2005) PCR-based detection of Babesia bovis and Babesia bigemina in their natural host Boophilus microplus and cattle. Int J Parasitol 35:105-111

Radostits OM, Gay CC, Hinchcliff KW, Constable PD (2008) Diseases associated with protozoa, 10th edn. In: Veterinary medicine: a textbook of diseases of cattle, horses, sheep, pigs and goats. Saunders Elsevier, $1483-1540$

Ramos CAN, Araújo FR, Souza IIF, Bacanelli G, Luiz HL, Russi LS, Oliveira RHM, Soares CO, Rosinha GMS, Alves LC (2011) Real-time polymerase chain reaction based on msa2c gene for detection of Babesia bovis. Vet Parasitol 176:79-83

Riek R (1964) The life cycle of Babesia bigemina (Smith and Kilborne, 1893) in the tick vector Boophilus microplus (Canestrini). Aust J Agric Res 15:802-821

Statistical Analyses System-SAS, 2002. SAS/INSIGHT user's guide, version 9 1.3, Version to Windows. SAS Institute, CD-ROM, Cary

Uilenberg G (1995) International collaborative research: significance of tick-borne hemoparasitic diseases to world animal health. Vet Parasitol 57(1-3):19-41

Vidotto O, Andrade GM, Amaral CHS, Barbosa CS, Freire RL, Rocha MA, Vidotto MC (1997) Frequência de anticorpos contra Babesia bigemina, Babesia bovis e Anaplasma marginale em rebanhos leiteiros da região de Londrina, Paraná. Arq Bras de Med Veterinária e Zootec 49:655-659 